\title{
Ophthalmoplegic Migraine: Inflammatory Neuropathy with Secondary Migraine?
}

\author{
HJ McMillan, DL Keene, P Jacob, P Humphreys
}

\begin{abstract}
Background: This critical review provides a summary of the clinical presentation, neuroimaging, treatment and prognosis in pediatric ophthalmoplegic migraine (OM). The features of $\mathrm{OM}$ are not in keeping with its classification as a migraine-variant. Method: We review 3 new and 37 reported pediatric OM cases. Results: Headache was an inconsistent feature, with $25 \%$ patients showing no evidence of pain at the initial OM episode. Patients demonstrated: 1) prolonged time for symptom resolution to occur (median time 3 weeks); 2) tendency for recurrent episodes to have more severe and persistent nerve involvement; 3 ) evidence of permanent neurological sequelae with recurrent episodes (30\% of patients); 4) rapid improvement and shortened duration with corticosteroid therapy and; 5) transient, reversible MRI contrast enhancement of the affected cranial nerve ( $86 \%$ of patients). These features would not be expected in primary migraine headache. Conclusion: A detailed understanding of the natural history of OM is essential for the clinical. This review provides support that OM may result from cranial nerve inflammation with headache a secondary and later feature of this condition.
\end{abstract}

RÉSUMÉ: La migraine ophtalmoplégique : s'agit-il d'une neuropathie inflammatoire avec migraine secondaire? Contexte : Cette revue présente un sommaire du tableau clinique, de la neuroimagerie, du traitement et du pronostic de la migraine ophtalmoplégique (MO) pédiatrique et une analyse critique ce ces données. Bien qu'on classifie la MO comme une forme variante de la migraine, ses manifestations ne cadrent pas avec cette classification. Méthode : Nous rapportons 3 nouvelles observations cliniques pédiatriques de MO et nous révisons 37 observations pédiatriques déjà rapportées. Résultats : La céphalée n'était pas toujours présente et $25 \%$ des patients n'avaient pas de douleur au moment du premier épisode de MO. À noter que : 1) les symptômes s'estompaient lentement (temps médian de 3 semaines) ; 2) au moment des rechutes, l'atteinte nerveuse avait tendance à être plus sévère et plus persistante ; 3) les patients ayant présenté plusieurs épisodes pouvaient avoir des signes de séquelles neurologiques permanentes (30\% des patients) ; 4) la corticothérapie provoquait une amélioration rapide et des épisodes plus courts et 5) un rehaussement transitoire réversible du nerf crânien atteint était observé à l'IRM avec produit de contraste (chez $86 \%$ des patients). On ne retrouve pas ces observations dans la céphalée migraineuse primaire. Conclusion : Le clinicien doit posséder une compréhension détaillée de l'histoire naturelle de la MO. Cette revue appuie l'hypothèse selon laquelle la MO résulte d'une inflammation d'un nerf crânien et la céphalée est secondaire et postérieure à cette pathologie.

Can. J. Neurol. Sci. 2007; 34: 349-355

Ophthalmoplegic migraine (OM) may be diagnosed after recurrent episodes of headache, followed by the paresis of one or more ocular cranial nerves (typically oculomotor ${ }^{1}$ ). The diagnosis requires all other causes of focal intracranial neuropathy (i.e. vascular, inflammatory, tumor or infectious etiology), to be excluded. Contrast MR imaging typically reveals enhancement of the affected nerve at the site of its exit from the brainstem. $^{2}$

Ophthalmoplegic migraine is rare, with an annual incidence estimated at 0.7 per million. ${ }^{3}$ However it does account for up to $7 \%$ of all isolated cases of childhood oculomotor nerve palsy. ${ }^{4,5}$
The initial episode of $\mathrm{OM}$ has been reported from three months of age ${ }^{6}$ into adulthood. ${ }^{7}$ While neurodevelopmental limitations may provide a challenge to the identification of headache,

\footnotetext{
From the Department of Pediatrics, Division of Neurology, Children's Hospital of Eastern Ontario, Ottawa, Ontario, Canada.

Received January 24, 2007. ACCEPTEd in Final FORm March 19, 2007. Reprint requests to: Daniel L. Keene, Department of Pediatrics, Division of Neurology, Children's Hospital of Eastern Ontario, 401 Smyth Road, Ottawa, ON, K1H 8L1, Canada.
} 
associated irritability, pallor or vomiting may provide indirect evidence of its presence. ${ }^{8}$

Controversy has surrounded the underlying mechanism of this disorder. Since episodes are transient and occur in otherwise healthy children, the opportunity does not exist for pathological examination. The early theory of $\mathrm{OM}$ attributed the ophthalmoplegia to a compressive neuropathy resulting from the vascular-dilatation phase of migraine. ${ }^{9}$ Not only did the "vascular theory" fail to provide an adequate explanation of migraine, so too did it fail to adequately describe the clinical features of OM. Large vessels would cause an extrinsic nerve compression which simply could not account for the frequent sparing of the pupil-response in this condition (pupillary fibres are more superficial and should be affected early with this mechanism). ${ }^{10}$

An autopsy study later identified smaller perforating arteries to frequently penetrate cranial nerves. ${ }^{11}$ It was postulated that internal or intrinsic compressive effects of the perforating arteries might offer a possible explanation to the clinical heterogeneity of $\mathrm{OM}$, but this theory still failed to explain the radiographic findings. Several other theories have been proposed, including: ischemic neuropathy, ${ }^{10}$ recurrent infection, ${ }^{12}$ recurrent demyelination-remyelination ${ }^{6}$ and/or inflammation. ${ }^{13}$ Post-mortem examination of adults, who previously met the criteria for ophthalmoplegic migraine, have demonstrated oculomotor nerve hypertrophy and scar formation in keeping with a recurrent demyelinating or inflammatory process. ${ }^{13,14}$

This paper provides a critical review of 40 cases of ophthalmoplegic migraine summarizing the clinical presentation, neuroradiographic findings and outcome of this condition. The results provide further support for Carlow's theory $^{13}$ that ophthalmoplegic migraine is indeed an inflammatory cranial neuropathy with the potential to result in subsequent or secondary head pain. Although the link between cranial nerve inflammation and headache remains unclear, the possibility of trigeminovascular activitation remains a very attractive possibility.

\section{Methods}

Three cases of pediatric ophthalmoplegic migraine were identified from the consulting practice of two child neurologists at the Children's Hospital of Eastern Ontario, Canada (presenting between 1999 - 2005). Previous case reports were obtained by a literature search of Pubmed using keywords: "ophthalmoplegic migraine". The bibliography of all case reports were reviewed in an attempt to identify additional patients. All English-language case reports between $1980-2005$ were included. Patients must have been $<18$ years old at the time of their initial episode. The following information was extracted; 1) age at time of initial event; 2) cranial nerve involved; 3) time to symptom resolution (initial and recurrent events); 4) type and result of neuroimaging performed; 5) use and result of corticosteroid therapy; 6) family history of migraine and; 7) evidence of permanent neurological damage. Cases that did not describe the physical examination were excluded.

\section{CASe Reports}

\section{Case 1}

A healthy, nine-year-old female presented with abrupt onset right partial oculomotor nerve paresis. She awoke complaining of diploplia and near-complete right ptosis. She had experienced a burning, right eye pain for several days prior, which had resolved prior to onset of ptosis. She denied other types of head pain, nausea, vomiting or photophobia. She was otherwise well with no fever or recent illness. She reported no change in visual acuity. Her medical history noted a two year history of recurrent, intermittent right retro-orbital and/or temporal headaches occurring roughly once per month with no associated symptoms or clear aggravating factors. There was no family history of migraine. Her father developed right Bell's palsy at age 53 with good recovery. On examination, she was alert and wellappearing. Her pupils were equal and briskly reactive to light and there was no relative afferent pupillary defect. Her visual acuity was normal. She had marked impairment of right eye adduction with attempted medial gaze. She had nearly complete right ptosis, being unable to open her right eye more than two millimetres. Her neurological exam was otherwise normal. Her complete blood count (CBC) and sedimentation rate (ESR) were normal. Magnetic resonance imaging (MRI) with gadolinium showed thickening and enhancement of the cisternal portion of her right oculomotor nerve. The MRA was normal. She was treated with prednisone (x 5 days at $2 \mathrm{mg} / \mathrm{kg}$, with subsequent dose-tapering). Re-examination on day 12 noted resolution of the right ptosis with some mild persistent difficulty with right eye adduction. She demonstrated complete clinical recovery over a two month period.

She continued to have intermittent episodes of right eye pain, lasting for several hours and occurring at roughly one month intervals (no association with menstrual cycle). She had no associated nausea, vomiting, photophobia and no ptosis or diplopia.

At age 12 years, she developed a recurrent episode of right eye pain associated with abrupt onset right pupil dilatation, diplopia and incomplete ptosis. On examination, a sluggish right pupillary response to light was noted. At rest, her right eye showed slight downward and lateral deviation, she was unable to fully adduct or elevate her right eye. She had incomplete right ptosis. The remainder of her exam was normal. The MRI with gadolinium showed pronounced thickening of the right oculomotor nerve, with a prominent area of contrast enhancement proximally at the site of exit from the midbrain (Figure 1).

Re-examination two months after the second episode noted complete resolution of ptosis, but with persistent mild diplopia. Her visual acuity was 20/20 OD (right) and 20/25 OS (left). Her pupils reacted normally. She had mild persistent right hypotropia, indicating mild residual weakness of right eye elevation. Fundoscopic examination was normal. Her clinical examination was returned to normal by ten weeks after the episode. A follow-up MRI with gadolinium ten weeks after her second episode noted resolution of abnormal enhancement of the right third cranial nerve, but persistent thickening of the previously enhancing segment (Figure 2). She has not had a recurrent episode over the past 18 months. 


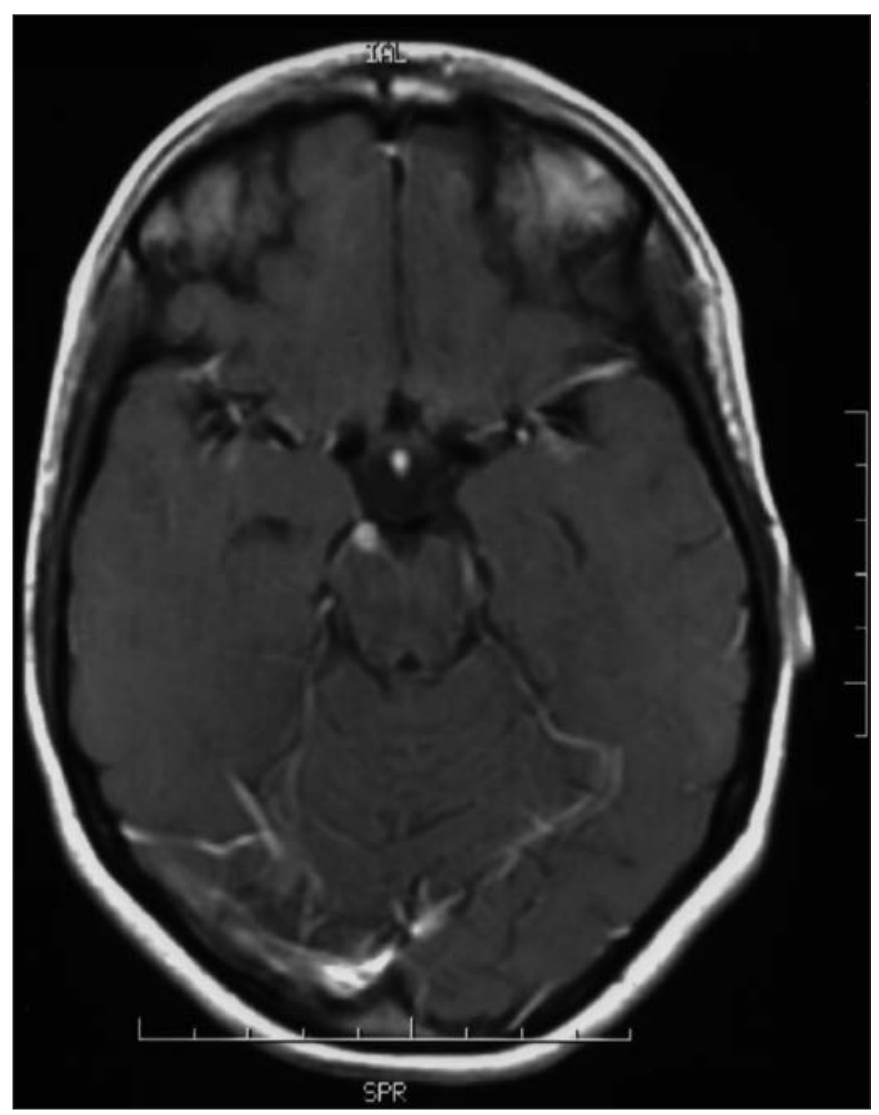

Figure 1: MRI with gadolinium enhancement, axial T2 FLAIR sequence, was completed during the acute phase of OM (Case 1). An area of prominent thickening and contrast enhancement was seen at the cisternal portion of the right oculomotor nerve, at its exit from the midbrain.

\section{Case 2}

A previously healthy, 12-month-old male presented with abrupt onset left ptosis and eye deviation. He had no preceding headache, pallor or irritability. There was no recent or intercurrent illness. He was otherwise healthy and developmentally normal. Family history of migraine was not present. Examination revealed an alert and well appearing male. His left eye was deviated downward and laterally and he demonstrated incomplete left ptosis. His pupils were equal and briskly reactive to light. His neurological examination was otherwise normal. CBC, ESR and CSF analysis were normal. Chest radiograph and skin tuberculin test (PPD) were negative. Magnetic resonance imaging of the head with gadolinium showed a small (3-4 mm) area of increased enhancement on the anterior surface of the left midbrain/cerebral peduncle at the site of exit of the left oculomotor nerve. The remainder of the brain was normal.

He was treated with prednisone $(2 \mathrm{mg} / \mathrm{kg}$; x10 days) with tapering over the following week. Rapid clinical improvement was noted in his left ptosis and ocular movements over 2-3 days. A repeat MRI with gadolinium three months later was normal.

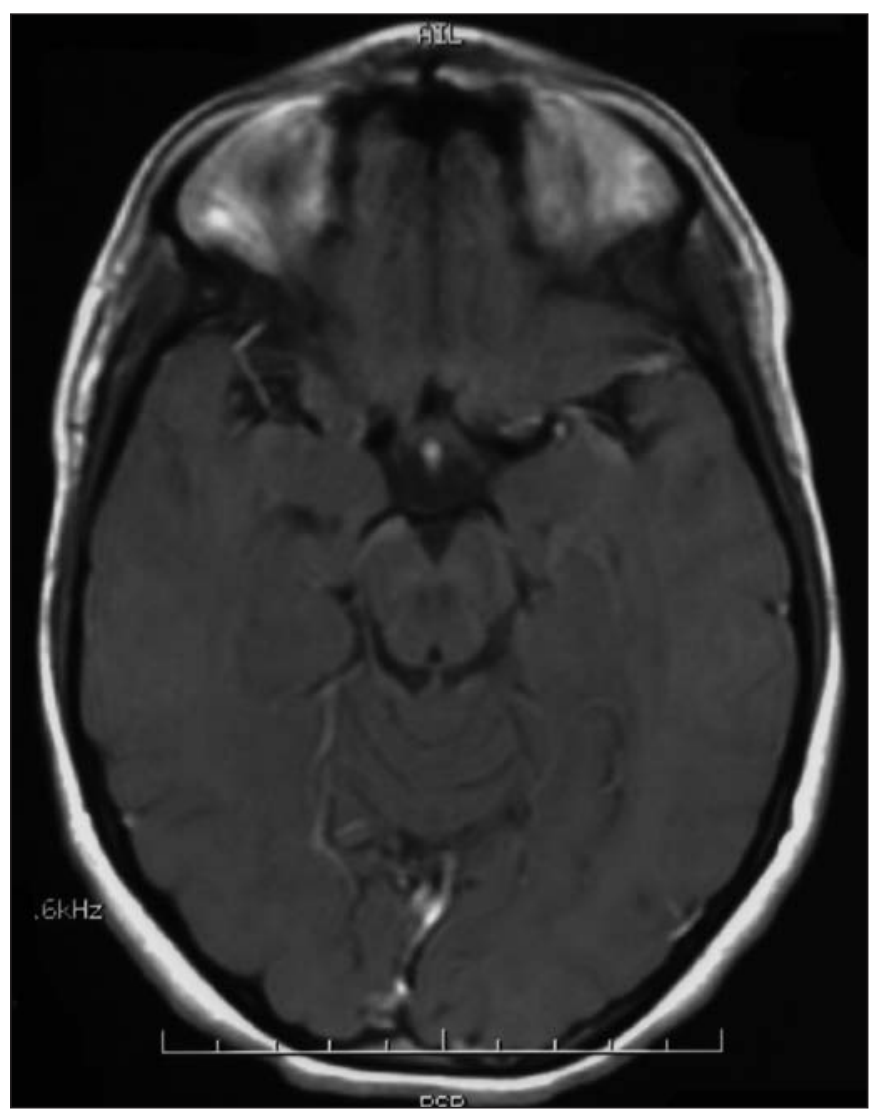

Figure 2: Repeat axial T2 FLAIR with gadolinium was completed ten weeks after the episode, and after symptom resolution was complete (Case 1). The enhancement of right oculomotor nerve had resolved, however, mild persistent thickening of the previously enhancing segment remained apparent.

He had two recurrent episodes at 17 and 23-months-of-age. They were identical in nature; abrupt in onset, with no preceding headache, irritability or pallor. Partial left oculomotor paresis was again noted. Neuroimaging was not repeated with these two recurrences.

His fourth episode, at 29-months-of-age, was preceded by severe pain and inconsolable crying for 2 - 3 days. The pain resolved with the onset of left partial oculomotor paresis, which became complete within two days. The left pupil response was also sluggish with this episode, which had not been noted with previous events. Repeat MRI again showed enhancement and thickening of the cistern portion of left oculomotor nerve. His symptoms resolved over 2 - 3 weeks, longer than with previous episodes.

At the age of 6 years, he continues to have periodic recurrence of complete left oculomotor paresis, with each episode taking longer to recuperate. He also has developed migraine without aura. Pizotifen therapy has proven beneficial for his migraine but has not altered the frequency of his ophthalmoplegic migraine. 
He has developed evidence of permanent neurological damage with relative mydriasis which does reacts well to light. No residual ptosis or ocular paresis are present.

\section{Case 3}

A healthy, 16-year-old female presented with abrupt onset right pupil dilatation, noted upon morning awakening. She had no associated change in visual acuity. She had noted a throbbing, right-sided headache with photophobia for two days. There was no associated nausea or vomiting, her headache had been similar to previous headaches which had occurred at roughly two-week intervals. She had no recent illness or trauma. Medical history revealed mild iron deficiency anemia and acne (treated with minocycline for four years). She was also taking an oral contraceptive agent. Examination showed mild obesity. The right pupil was dilated $5 \mathrm{~mm}$ and was unreactive to light. The left pupil was $3 \mathrm{~mm}$ and briskly reactive. Her visual acuity and field testing were normal. Her extraocular eye movements were normal and conjugate. There was no ptosis. Her fundoscopic exam was normal with no evidence of papilloedema. Her neurological exam was otherwise intact. Her CBC and ESR were normal. Initial $\mathrm{CT}$ head and MRI/MRA head without enhancement were normal. Repeat MRI head with gadolinium completed two weeks later, revealed definite enhancement of the cistern portion of the right oculomotor nerve. She did not receive prednisone therapy and her symptoms completely resolved within weeks. She has gone 18 months without recurrence.

\section{Literature REVIEW}

The initial episode of ophthalmoplegic migraine (OM) has been reported as early as age 3 months $^{6}$ (Table 1 ). The mean and median age at the initial episode was 4.2 and 2 years respectively. Gender showed a slight female predilection: 25 females and 15 males (Table 2).

Headache was a variable and inconsistent feature of ophthalmoplegic migraine. Headache, eye pain and/or irritability were not present during the initial episode of ophthalmoplegia in at least ten cases (25\%). Seven patients exhibited headache only after recurrent episodes, and three did not develop irritability or headache despite multiple attacks. ${ }^{4,15}$ The three patients demonstrating ophthalmoplegia without headache were included in the review as they met all other diagnostic criteria and demonstrated reversible enhancement of the affected cranial nerve. We caution that the initial pain-free episodes of OM may in fact be underestimated. There may be a tendency for physicians to under-report such cases (as they do not fit the current definition of $\mathrm{OM}$ ). Furthermore, several of the cases in our review found the earlier or initial episodes of ophthalmoplegia to also be less clinically apparent and persist for shorter durations.

When present, headache typically preceded onset of ocular symptoms by several days. Only one report ${ }^{16}$ described headache developing five days after onset of ptosis. Head pain has been described as sharp retro-orbital pain ${ }^{6}$ or inner-canthus eye pain (Case 1). The more "typical" migraine headache (throbbing pain in the frontal, retro-orbital or temporal regions) appears more often among adolescent and adult OM patients. ${ }^{17-19}$ Associated "migraine symptoms" (nausea, vomiting, photophobia) were present in only 12 patients $(35 \%)$.

Fifteen patients $(37 \%)$ had a first-degree family member with migraines with an additional five (12\%) having only seconddegree family member with migraine.

Oculomotor nerve (CN 3) was the most commonly involved. Isolated oculomotor nerve involvement was noted in 38 (95\%) of cases. One patient demonstrated an isolated right abducens nerve involvement; ${ }^{20}$ another, involvement of the left oculomotor and abducens nerve. ${ }^{6}$ Without exception, recurrent episodes always affected the same cranial nerve and recurred on the same side.

Symptom onset was most often "abrupt" (ie. symptoms noted upon awakening); four patients however, reported gradual onset of ocular symptoms (ie. taking 24 hours $^{21}$ to as long as 7-10 days $^{15}$ to slowly progress to maximum ocular symptoms).

Recurrent episodes were noted to have a greater likelihood of 1) longer time for symptom resolution, 2) more severe or pronounced ocular symptoms and 3) resulting in permanent neurological sequelae.

The median time for symptom resolution of the initial episode was three weeks, with a range of "hours" 22 to three months. ${ }^{13}$ All patients did eventually demonstrate complete symptom resolution after the initial episode. Twenty patients $(50 \%)$ required $\geq 3$ weeks for complete symptom resolution. In some cases recurrent episodes persisted for longer durations, $4,16,22$ although it should be noted that such cases did not employ corticosteroid treatment.

Recurrent episodes may become increasingly severe. This was noted in our patient (Case 2), similar to other reports of initially partial transient ophthalmoplegia progressing to complete ophthalmoplegia with recurrent episodes. ${ }^{16,22}$

The interval between initial and recurrence of ophthalmoplegia varied from as little as weeks, ${ }^{2}$ to up to 5-7 years. ${ }^{22-24}$

Permanent neurological sequelae after repeated episodes have been reported in $12(30 \%)$ of cases. The deficits ranged from permanent residual oculomotor weakness, ${ }^{25}$ permanent mydriasis, ${ }^{22,26}$ to permanent, nearly total oculomotor paralysis. ${ }^{23}$ A report of persistent abducens nerve palsy with recurrent episodes also exists. ${ }^{27}$

Prednisone has been used frequently for treatment of ophthalmoplegic migraine. Six reports clearly document a dramatic decrease in the time to symptom resolution with prednisone compared to the initial episode where prednisone had not been used..$^{6,8,20,23,25,28} \mathrm{Kandt}^{28}$ documented a rapid response to prednisone therapy followed by "relapse" of ophthalmoplegia when steroids were abruptly discontinued after eight days. Symptoms again rapidly resolved with treatment reinstitution, there was no further recurrence with a more gradual taper. Prednisone has also been reported to have a possible abortive role when taken at the earliest sign of symptom onset. ${ }^{20}$ Only one report failed to demonstrate a beneficial effect from prednisone therapy, ${ }^{4}$ although the dose and timing of therapy in this case was unclear.

Magnetic resonance imaging with gadolinium enhancement was completed in $21 / 40$ patients. Eighteen $(86 \%)$ demonstrated enhancement of the affected cranial nerve during the acute episode of ophthalmoplegia which, when repeated during the convalescent phase, showed resolution. Cranial nerve thickening 
Table 1: Literature review: Pediatric ophthalmoplegic migraine

\begin{tabular}{|c|c|c|c|c|c|c|c|c|}
\hline Author: & $\begin{array}{l}\text { Initial } \\
\text { event }\end{array}$ & Sex & $\begin{array}{l}\text { CN } \\
\text { involved }\end{array}$ & $\begin{array}{l}\text { Time to } \\
\text { symptom } \\
\text { resolution }\end{array}$ & $\begin{array}{l}\text { MRI + } \\
\text { gadolinium } \\
\text { done? }\end{array}$ & Enhancement: & Recurrence: & $\begin{array}{l}\text { anent } \\
\text { ge: }\end{array}$ \\
\hline \multirow[t]{3}{*}{ Current Series } & $12 \mathrm{mos}$ & $\mathrm{M}$ & $\mathrm{L} \mathrm{CN} 3$ & 2-3 days & Yes & Enhancement at exit from midbrain & Yes: $17,23 \& 29$ mos old & No \\
\hline & $9 \mathrm{yr}$ & $\mathrm{F}$ & $\mathrm{R} \mathrm{CN} 3$ & $2 \operatorname{mos}$ & Yes & Enhancement of cisternal portion & Yes: $12 \mathrm{yr}$ old & No \\
\hline & $16 \mathrm{yr}$ & $\mathrm{F}$ & $\mathrm{R} \mathrm{CN} 3$ & "weeks" & Yes & Enhancement of cisternal portion & No & No \\
\hline Amit (32) & $14 \mathrm{mos}$ & $\mathrm{F}$ & L CN 3 & "hours" & $\mathrm{No}^{1}$ & & Yes: 2yr old & No \\
\hline Bailey (21) & $2 \mathrm{yr}$ & $\mathrm{F}$ & R CN 3 & 13 days & $\mathrm{No}^{1}$ & & Yes: $3,4,5 y r$ old & Yes \\
\hline \multirow{6}{*}{ Carlow (13) } & $2 \mathrm{yr}$ & $\mathrm{F}$ & $\mathrm{CN} 3$ & $3 \mathrm{mos}$ & Yes & Enhancement of at exit from midbrain & Yes & No \\
\hline & $3 \mathrm{yr}$ & $\mathrm{M}$ & CN 3 & 4 weeks & Yes & As above & Yes & Yes \\
\hline & $18 \mathrm{mos}$ & $\mathrm{F}$ & $\mathrm{CN} 3$ & 4 weeks & Yes & As above & Yes & Yes \\
\hline & $18 \mathrm{mos}$ & $\mathrm{F}$ & CN 3 & 4 weeks & Yes & As above & Yes & Yes \\
\hline & $9 \mathrm{yr}$ & $\mathrm{F}$ & $\mathrm{CN} 3$ & 2 weeks & Yes & As above & Yes & Yes \\
\hline & $5 \mathrm{yr}$ & $\mathrm{F}$ & $\mathrm{CN} 3$ & 2 weeks & Yes & As above & Yes & No \\
\hline \multirow[t]{2}{*}{ Durkan (4) } & $12 \mathrm{mos}$ & $\mathrm{F}$ & L CN 3 & 3 weeks & $\mathrm{No}^{1}$ & & Yes: 2y6mos & No \\
\hline & $2 \mathrm{yr}$ & $\mathrm{M}$ & R CN 3 & 3 weeks & $\mathrm{No}^{1}$ & & Yes: 5yr old & No \\
\hline \multirow[t]{2}{*}{ Elser (25) } & $5 \mathrm{mos}$ & $\mathrm{F}$ & $\mathrm{R} \mathrm{CN} 3$ & 3 weeks & No & & Yes: $8,11 \mathrm{mos}$ old, then frequent & Yes \\
\hline & $7 \mathrm{mos}$ & $\mathrm{M}$ & R CN 3 & 3 weeks & $\mathrm{No}^{1}$ & & Yes: $1-3 x / \operatorname{mos}$ & Yes \\
\hline Kandt (28) & $2 \mathrm{y} 6 \mathrm{mos}$ & $\mathrm{F}$ & $\mathrm{R} \mathrm{CN} 3$ & 5 weeks & $\mathrm{No}^{1}$ & & Yes: 4y $8 \mathrm{mos}, 6 \mathrm{yr}$ old & No \\
\hline Katz (16) & $9 \mathrm{yr}$ & $\mathrm{F}$ & $\mathrm{L} \mathrm{CN} 3$ & 2 days & $\mathrm{No}^{1}$ & & Yes: $10,11,12$ yr old & No \\
\hline \multirow[t]{4}{*}{ Lance (6) } & $9 \operatorname{mos}$ & $\mathrm{F}$ & L CN 3 & $2-10$ days & $\mathrm{Yes}^{2}$ & $\begin{array}{l}\text { Enhancement at exit from brainstem \& } \\
\text { along line of nerve }\end{array}$ & Yes: 2 per year & No \\
\hline & $3 \mathrm{mos}$ & $\mathrm{M}$ & R CN 3 & not reported & No & & Yes: frequent & No \\
\hline & $5 \mathrm{yr}$ & $\mathrm{M}$ & $\mathrm{R} \mathrm{CN} 3$ & 10 days & $\mathrm{No}^{1,3}$ & & Yes & No \\
\hline & $13 \mathrm{yr}$ & $\mathrm{M}$ & $\mathrm{L} \mathrm{CN} \mathrm{3,6}$ & 3 weeks & $\mathrm{No}^{1,3}$ & & Yes: $14 \mathrm{yr}$ old & No \\
\hline \multirow[t]{2}{*}{ O'Hara (26) } & $4 \mathrm{yr}$ & $\mathrm{F}$ & R CN 3 & 6 weeks & $\mathrm{Yes}^{2}$ & $\begin{array}{l}\text { Enhancing cisternal portion of thickened } \\
\text { nerve }\end{array}$ & Yes: 7yr old & No \\
\hline & $21 \mathrm{mos}$ & $\mathrm{M}$ & L CN 3 & "rapid" & Yes & Enhancing cisternal portion of nerve & Yes: 3 attacks in $12 \mathrm{mos}$ & Yes \\
\hline \multirow[t]{2}{*}{ Oostergaard (23) } & $7 \mathrm{mos}$ & $\mathrm{F}$ & L CN 3 & "weeks" & $\mathrm{No}^{4}$ & & Yes: 13,20 mos old & Yes \\
\hline & $18 \mathrm{mos}$ & $\mathrm{F}$ & L CN 3 & 6 weeks & $\mathrm{Yes}^{2}$ & $\begin{array}{l}\text { Enhancement of thickened nerve } \\
\text { ("swollen from brainstem to cavernous } \\
\text { sinus") }\end{array}$ & Yes: $4.5,6 y r$ old & No \\
\hline \multirow[t]{3}{*}{ Prats (22) } & $11 \mathrm{yr}$ & $\mathrm{F}$ & $\mathrm{L} \mathrm{CN} 3$ & 3 days & $\mathrm{Yes}^{2}$ & $\begin{array}{l}\text { Enhancing cisternal portion }(3 \mathrm{~mm}) \text { of } \\
\text { nerve }\end{array}$ & Yes: $12 \mathrm{y} 9 \mathrm{mos}$ old & No \\
\hline & "infant" & $\mathrm{M}$ & L CN 3 & 3-4 days & $\mathrm{Yes}^{2}$ & $\begin{array}{l}\text { Enhancing cisternal portion }(5 \mathrm{~mm}) \text { of } \\
\text { nerve }\end{array}$ & Yes: $3 y$ old & Yes \\
\hline & $6 \mathrm{yr}$ & $\mathrm{F}$ & L CN 3 & "hours" & $\mathrm{No}^{3}$ & & Yes: sporadic & No \\
\hline Prats (22) & $3 \mathrm{y} 6 \mathrm{mos}$ & $\mathrm{F}$ & $\mathrm{L} \mathrm{CN} 3$ & 2 weeks & $\mathrm{No}^{1}$ & & Yes: $10 \mathrm{yr}$ & No \\
\hline Ramelli (24) & $20 \mathrm{mos}$ & $\mathrm{F}$ & R CN 3 & 2 weeks & Yes & Enhancing nerve at pentagonal cistern & Yes: 6yr old & No \\
\hline \multirow[t]{2}{*}{ Shin (30) } & $7 \mathrm{yr}$ & $\mathrm{M}$ & $\mathrm{L} \mathrm{CN} 3$ & 15 days & Yes & NO enhancement & Yes: 8yr old & No \\
\hline & $6 y \mathrm{r}$ & $\mathrm{F}$ & $\mathrm{R} \mathrm{CN} 3$ & 15-20 days & Yes & NO enhancement & Yes: 6-11yr old & No \\
\hline Smith (20) & $18 \mathrm{mos}$ & $\mathrm{M}$ & R CN 6 & $6-8$ weeks & No & & Yes: $5 x /$ year & No \\
\hline Stidham (15) & $3 \mathrm{yr}$ & $\mathrm{F}$ & R CN 3 & 6 weeks & $\mathrm{No}^{1,3}$ & & Yes: recurrent painless episodes & No \\
\hline Stommel (17) & $18 \mathrm{yr}$ & $\mathrm{M}$ & R CN 3 & 7 days & Yes & Enhancing at point of exit (midbrain) & No & No \\
\hline Troost (33) & $3 \mathrm{yr}$ & M & L CN 3 & 3 weeks & No & & Yes: $4.5,5.5 \mathrm{yr}$ old & No \\
\hline Weiss (34) & $2 \mathrm{yr}$ & $\mathrm{F}$ & $\mathrm{L} \mathrm{CN} 3$ & 2 days & $\mathrm{Yes}^{2}$ & NO enhancement & Yes: $7 \mathrm{yr}$ old & No \\
\hline Wong (2) & $6 \mathrm{yr}$ & $\mathrm{M}$ & $\mathrm{L} \mathrm{CN} 3$ & 4 days & Yes & Enhancing cisternal portion of nerve & Yes: 6 weeks later & No \\
\hline \multirow[t]{2}{*}{ Woody (8) } & $5 \mathrm{mos}$ & $\mathrm{F}$ & R CN 3 & 3 weeks & No & & Yes: 8,11 mos old, then frequent & Yes \\
\hline & $7 \mathrm{mos}$ & $\mathrm{M}$ & R CN 3 & 3 weeks & No & & Yes: $1-3 x$ per mos & Yes \\
\hline
\end{tabular}

[1] indicates CT head normal, [2] indicates that MRI was not done for initial episode, but was completed during a subsequent, recurrent episode,

[3] indicates MRI without gadolinium was normal, [4] indicates MRI without gadolinium showed no enhancement but CN appeared thickened 
Table 2: Summary of collated data: ophthalmoplegic migraine literature review

\begin{tabular}{|c|c|}
\hline Total number cases: & 40 \\
\hline Sex ratio: & 25 female : 15 male \\
\hline \multicolumn{2}{|l|}{ Age at initial event: } \\
\hline Mean: & $\begin{array}{l}4.2 \text { yrs }(\mathrm{N}=39 \text { for } \\
\text { calculation of mean })\end{array}$ \\
\hline Median: & $2 \mathrm{yrs}$ \\
\hline Range & $3 \mathrm{mos}$ to $18 \mathrm{yrs}$ \\
\hline Age $<2$ yrs & $21(53 \%)$ \\
\hline Age $<5$ yrs & $29(73 \%)$ \\
\hline \multicolumn{2}{|l|}{ Headache/irritable with initial event: } \\
\hline Yes: & $30(75 \%)$ \\
\hline No: & $10(25 \%)$ \\
\hline \multicolumn{2}{|l|}{ Headache-free patients developing } \\
\hline headache with recurrence: & $7 / 10(70 \%)$ \\
\hline \multicolumn{2}{|l|}{ Cranial nerve involvement: } \\
\hline III alone: & $\begin{array}{l}38 \text { (16 right; } 16 \text { left; } \\
6 \text { not stated) }\end{array}$ \\
\hline VI alone: & 1 \\
\hline III and VI: & 1 \\
\hline \multicolumn{2}{|l|}{ Pupillary involvement $(\mathrm{N}=39)$ : } \\
\hline Intact (spared): & $23 \%$ \\
\hline Involved (partial or complete) & $77 \%$ \\
\hline \multicolumn{2}{|l|}{ Duration of ocular symptoms: } \\
\hline Mean: & $\begin{array}{l}21.8 \text { days }(\mathrm{N}=36 \text { for } \\
\text { calculation of mean })\end{array}$ \\
\hline Median: & $3 \mathrm{wks}$ \\
\hline Range: & "Hours" to $3 \mathrm{mos}$ \\
\hline \multicolumn{2}{|l|}{ Family history of migraines: } \\
\hline First-degree relatives: & $37 \%$ \\
\hline Extended relatives only: & $15 \%$ \\
\hline $\begin{array}{l}\text { Patients receiving MRI with gadolinium } \\
\text { Enhancement of affected nerve }\end{array}$ & $18(86 \%)$ \\
\hline
\end{tabular}

was also noted on both MRI and CT head among patients that had experienced recurrent episodes. ${ }^{23}$ The MR without enhancement was completed for five (one showed thickening from prepontine cistern to cavernous sinus, other studies were unremarkable), and the CT head was completed for eight patients. Six patients did not receive neuroimaging.

Two of the patients had only a single episode of ocular symptoms with the episodes occurring at age $18 \mathrm{yrs}^{17}$ and $16 \mathrm{yrs}$ (Case 3). These patients otherwise fit the established criteria: headache present and absence of other demonstrable causes of transient, reversible ocular symptoms. Furthermore, they both exhibited MRI enhancement of cisternal portion of the affected nerve which showed resolution with repeat convalescent imaging. As such they were also included in the analysis.

\section{DisCUSSION}

Our cases and previous published cases had the following features that would not be expected in a primary migrainous condition: 1) prolonged time for symptom resolution to occur (median time, three weeks); 2) recurrent episodes showing increasingly severe ocular nerve involvement and longer duration of attacks; 3) permanent neurological sequelae with recurrent episodes (30\% patients); 4) rapid improvement and shortened duration with corticosteroid therapy; 5) a report of ophthalmoplegia "relapse" upon withdrawal of short-course of steroid therapy and; 6) transient, reversible MRI contrast enhancement of the affected cranial nerve $(86 \%$ patients receiving enhanced MR studies). These features suggest that ophthalmoplegic migraine shows clinical and radiographic features of a recurrent inflammatory cranial neuropathy.

Headache description and progression would favour inflammation rather than migraine, as headache and irritability were absent in $25 \%$ of patients at the time of initial ocular symptoms. Initially, when headache was present, it was often described as retro-orbital, eye or inner canthus pain, reminiscent of the ocular pain described in patients with optic neuritis. Headache became a more reliable feature with recurrent attacks, assuming a more typical migrainous pattern at that time.

These cases are readily differentiated from Tolosa-Hunt syndrome by the lack of involvement of the cavernous sinus (34/40 had CT and/or MR imaging), instead showing consistent involvement of the cisternal portion of oculomotor nerve in all cases where enhancement was identified.

The inflammatory theory of migraine ${ }^{29}$ proposes that a chemical mediator may activate trigeminovascular axons resulting in neuropeptide release and a subsequent sterile inflammatory response. It is only with orthodromic conduction along trigeminovascular fibres to higher cortical structures that nociceptive registration and perception is thought to occur.

Local inflammation could also account for the clinical variability demonstrated in this condition. We are in agreement with Vijayan ${ }^{10}$ that the variability in pupillary involvement (pupillary response spared in $21 \%$, only partial involvement in at least 28\%), does not favour vascular compression as a model for OM. In fact, reports of vascular changes during the active phase of OM, noted with cerebral angiogram, ${ }^{9}$ may be the consequence (due to inflammation) rather than the cause of OM. Two patients with early contrast MR imaging that failed to show cranial nerve enhancement,${ }^{30}$ nevertheless demonstrated decreased perfusion on SPECT scan, an imaging feature which may be in keeping with local inflammation and edematous change.

If the ophthalmoplegia does result from an inflammatory cranial neuropathy, we hypothesize that it may predispose some patients (particularly with recurrent episodes) to develop headache or migraine. This is supported by the $70 \%$ of initially "headache-free patients developing migraine only with OM recurrence. There is increasing evidence that classic migraine may in fact be viewed as a neurogenic inflammatory disorder rather than a primary disorder of vascular smooth muscle. ${ }^{31}$ Carlow ${ }^{13}$ hypothesized that a similar inflammatory process, with the associated release of vasoactive neuropeptides and proinflammatory mediators, may activate the trigeminovascular system and give rise to migraine. Our findings lend further support to his hypothesis.

Our review provides clinical and radiographic support that "ophthalmoplegic migraine" is a recurrent inflammatory cranial neuropathy. Headache is an important, but often secondary feature of this condition. As such, classifying this condition as a migraine variant may have the disadvantageous result of 
delaying or taking an initial "wait and watch" approach with regard to treatment. Prompt corticosteroids therapy has proven beneficial at decreasing the duration of symptoms in the majority of OM cases where it has been used. This raises the important question as to whether corticosteroids may have a role at arresting the pattern of increasing clinical severity or avoiding permanent neurological deficit which is seen in a third of patients with recurrent episodes. On this basis, we advocate the reclassification of ophthalmoplegic migraine as a recurrent cranial neuropathy typically associated with secondary migraine.

\section{REFERENCES}

1. Headache Classification Subcommittee of the International Headache Society. The international classification of headache disorders. 2nd ed. Cephalalgia. 2004; 24 Suppl 1: 9-160.

2. Wong V, Wong WC. Enhancement of oculomotor nerve: a diagnostic criterion for ophthalmoplegic migraine? Pediatr Neurol. 1997; 17: 70-3.

3. Hansen SL, Borelli-Moller L, Strange P, Nielson BM, Olesen J. Ophthalmoplegic migraine: diagnostic criteria, incidence of hospitalization and possible etiology. Acta Neurol Scand. 1990; 81: 54-60.

4. Durkan GP, Troost BT, Slamovits TL, Spoor TC, Kennerdell JS. Recurrent painless oculomotor palsy in children. A variant of ophthalmoplegic migraine? Headache. 1981; 21: 58-62.

5. Miller NR. Solitary oculomotor nerve palsy in childhood. Am J Ophthalmol. 1977; 83: 106-11.

6. Lance JW, Zagami AS. Ophthalmoplegic migraine: a recurrent demyelinating neuropathy? Cephalalgia. 2001; 21: 84-9.

7. Celebisoy N, Sirin H, Gokcay F. Ophthalmoplegic migraine: two patients, one at middle age with abducens palsy. Cephalalgia. 2004; 25 : 151-3.

8. Woody RC, Blaw ME. Ophthalmoplegic migraine in infancy. Clin Pediatr. 1986; 25: 82-4.

9. Walsh JP, O'Doherty DS. A possible explanation of the mechanism of ophthalmoplegic migraine. Neurology. 1960; 10: 1079-84.

10. Vijayan N. Ophthalmoplegic migraine: ishemic or compressive neuropathy? Headache. 1980; 20: 300-4.

11. Milisavljevic M, Marinkovic S, Lolic-Draganic V, Kovacevic M. Oculomotor, trochlear, abducens nerve penetrated by cerebral vessels. Arch Neurol 1986; 43: 58-61.

12. Mark AS, Casselman J, Brown D, Sanchez J, Kolsky M, Larsen TC, et al. Ophthalmoplegic migraine: reversible enhancement and thickening of the cisternal segment of the oculomotor nerve on contrast-enhanced MR images. Am J Neuroradiol. 1998; 19: 1887-91.

13. Carlow TJ. Oculomotor ophthalmoplegic migraine: is it really a migraine? J Neuroophthamol. 2002; 22: 215-21.

14. Carlow TJ. Oculomotor ophthalmoplegic migraine: what really causes it? J Neuroophthamol. 2003; 23: 240-1.
15. Stidham DB, Butler IJ. Recurrent isolated ptosis in presumed ophthalmopleic migraine of childhood. Ophthalmology. 2000; 107: 1476-8.

16. Katz B, Rimmer S. Ophthalmoplegic migraine with superiour ramus oculomotor paresis. J Clin Neuroopthamol. 1989; 9: 181-3.

17. Stommel EW, Ward TN, Harris RD. MRI findings in a case of ophthalmoplegic migraine. Headache. 1993; 33: 234-7.

18. De Silva DA, Siow JC. A case report of ophthalmoplegic migraine: a differential diagnosis of third nerve palsy. Cephalalgia. 2005; 25: 827-30.

19. Van der Dussen DH, Bloem BR, Liauw L, Ferrari MD. Ophthalmoplegic migraine: migrainous or inflammatory. Cephalalgia. 2004; 24: 312-5.

20. Smith CD, Reeves AG. Amelioration of ophthalmoplegic migraine by prednisone: a case report. Headache. 1986; 26: 93-4.

21. Bailey TD, O'Connor PS, Tredici TJ, Shacklett DE. Ophthalmoplegic migraine. J Clin Neuroophthalmol. 1984; 4: 225-8.

22. Prats JM, Mateos B, Garaizar C. Resolution of MRI abnormalities of the oculomotor nerve in childhood ophthalmoplegic migraine. Cephalalgia. 1999; 19: 655-9.

23. Ostergaard, JR, Moller HU, Christensen T. Recurrent ophthalmoplegia in childhood: diagnostic and etiologic considerations. Cephalalgia. 1996; 16: 276-9.

24. Ramelli GP, Vella S, Loublad K, Remonda L, Vassella F. Swelling of the third nerve in a child with transient oculomotor paresis: a possible cause for ophthalmoplegic migraine. Neuropediatrics. 1999; 31: 145-7.

25. Elser JM, Woody RC. Migraine headache in the infant and young child. Headache. 1990; 30: 366-8.

26. O'Hara MA, Anderson RT, Brown D. Magnetic resonance imaging of ophthalmoplegic migraine of children. J AAPOS. 2001; 5: $307-10$.

27. De Renzi E, Nichelli P. Ophthalmoplegic migraine with persistent abducens nerve palsy. Eur Neurol. 1977; 15: 227-30.

28. Kandt RS, Goldstein, GW. Steroid-responsive ophthalmoplegia in a child. Arch Neurol. 1985; 42: 589-91.

29. Sanchez del Rio M, Reuter U, Moskowitz MA. Central and peripheral mechanisms of migraine. Funct Neurol. 2000; 15 Suppl 3; 157-62.

30. Shin DJ, Kim JH, Kang SS. Ophthalmoplegic migraine with reversible thalamic ischemia shown by brain SPECT. Headache. 2002; 42: 132-5.

31. Waeber C, Moskowitz MA. Migraine as an inflammatory disorder. Neurology. 2005; 64: S9-S15.

32. Amit R, Benezra D. Oculomotor ophthalmoplegic migraine in an infant. Headache. 1987; 27: 390-1.

33. Troost BT. Ophthalmoplegic migraine. Biomed Pharmacother. 1996; 50: 49-51.

34. Weiss AH, Phillips JO. Ophthalmoplegic migraine. Pediatr Neurol. 2004; 30: 64-6. 